University of Wollongong

Research Online

$1-1-2019$

Impact of body mass index on utilization of selected hospital resources for four common surgical procedures

Luke Freckelton

Wollongong Hospital

Kelly Lambert

University of Wollongong, klambert@uow.edu.au

Natalie A. Smith

University of Wollongong, natsmith@uow.edu.au

Victoria J. Westley-Wise

University of Wollongong, victoria@uow.edu.au

Luise P. Lago

University of Wollongong, lago@uow.edu.au

See next page for additional authors

Follow this and additional works at: https://ro.uow.edu.au/ahsri

Research Online is the open access institutional repository for the University of Wollongong. For further information contact the UOW Library: research-pubs@uow.edu.au 


\title{
Impact of body mass index on utilization of selected hospital resources for four common surgical procedures
}

\author{
Abstract \\ Background: Evidence about the impact of obesity on surgical resource consumption in the Australian \\ setting is equivocal. Our objectives were to quantify the prevalence of obesity in four frequently \\ performed surgical procedures and explore the association between body mass index (BMI) and hospital \\ resource utilization including procedural duration, length of stay (LOS) and costs. \\ Methods: A retrospective cohort study of patients undergoing four surgical procedures at a tertiary \\ referral centre in New South Wales, between 1 January 2016 and 31 December 2016, was conducted. The \\ four surgical procedures were total hip replacement, laparoscopic appendectomy, laparoscopic \\ cholecystectomy and hysteroscopy with dilatation and curettage. Surgical groups were stratified \\ according to BMI category. \\ Results: A total of 699 patients were included in the study. The prevalence of obesity was significantly \\ higher than local and national population estimates for all procedures except appendectomy. BMI was not \\ associated with increased hospital resource utilization (procedural, anaesthetic or intensive care stay \\ duration) in any of the four surgical procedures examined after controlling for age, gender and complexity. \\ For other outcomes of hospital resource utilization (LOS and cost), the relationship was inconsistent \\ across the four procedures examined. A high BMI was positively associated with higher LOS, medical \\ costs and allied health costs in those who underwent an appendectomy, and critical care costs in those \\ who underwent laparoscopic cholecystectomy. \\ Conclusion: Obesity was common in patients undergoing four frequently performed surgical procedures. \\ The relationship between $\mathrm{BMI}$ and hospital resource utilization appears to be complex and varies across \\ the four procedures examined.

\section{Publication Details} \\ L. Freckelton, K. Lambert, N. A. Smith, V. Westley-Wise, L. Lago \& J. Mullan, "Impact of body mass index \\ on utilization of selected hospital resources for four common surgical procedures", ANZ Journal of \\ Surgery 89 7-8 (2019) 842-847.

\section{Authors} \\ Luke Freckelton, Kelly Lambert, Natalie A. Smith, Victoria J. Westley-Wise, Luise P. Lago, and Judy Mullan
}




\section{$\underline{\text { Abstract }}$}

\section{Background}

Evidence about the impact of obesity on surgical resource consumption in the Australian setting is equivocal. Our objectives were to quantify the prevalence of obesity in four frequently performed surgical procedures and explore the association between body mass index (BMI) and hospital resource utilisation including procedural duration, length of stay (LOS) and costs.

\section{Methods}

A retrospective cohort study of patients undergoing four surgical procedures at a tertiary referral centre in New South Wales, between 01 January 2016 and 31 December 2016, was conducted. The four surgical procedures were total hip replacement, laparoscopic appendectomy, laparoscopic cholecystectomy, and hysteroscopy with dilatation and curettage. Surgical groups were stratified according to BMI category.

\section{Results}

A total of 699 patients were included in the study. The prevalence of obesity was significantly higher than local and national population estimates for all procedures except appendectomy. BMI was not associated with increased hospital resource utilisation (procedural, anesthetic or intensive care stay duration) in any of the four surgical procedures examined after controlling for age, gender and complexity. For other outcomes of hospital resource utilisation (LOS and cost), the relationship was inconsistent across the four procedures examined. A high BMI was positively associated with higher LOS, medical costs and allied health costs in those who underwent an appendectomy, and critical care costs in those who underwent laparoscopic cholecystectomy. 


\section{Conclusion}

Obesity was common in patients undergoing four frequently performed surgical procedures. The relationship between BMI and hospital resource utilisation appears to be complex and varies across the four procedures examined. 


\section{Introduction}

The public health burden of disease related to obesity is rapidly increasing (1) and is associated with rising health care costs (2). Recent data indicates that nearly two thirds of Australian adults are overweight or obese (3). Obesity is also a risk factor for health conditions such as heart disease and diabetes (4).

Literature exploring the relationship between obesity and surgical outcomes is extensive. Obesity is a risk factor for post-operative complications (5), longer operating times (6), and increased hospital costs (7). Obese patients represent a diagnostic challenge for the surgeon (8), and require additional surgical preparation (9), and time to assess anaesthetic and operative risks (10). Bariatric equipment and supplementary staff may also be necessary (11).

However, the relationship between obesity and outcomes is variable and complicated by the type of procedure performed and surgical approach used (12). One retrospective review of patients undergoing total hip replacement (THR) reported a 5\% higher cost for every 1 unit increment of Body Mass Index (BMI) above $30 \mathrm{~kg} / \mathrm{m}^{2}$ (13). In another study a BMI greater than $30 \mathrm{~kg} / \mathrm{m}^{2}$ was associated with higher rates of infection and venous thromboembolism (14). In contrast, obesity was not associated with worse outcomes in patients undergoing THR (15). Evidence about the impact of obesity on outcomes in other common surgical procedures, such as appendectomy, cholecystectomy and hysteroscopy (16) is also conflicting (17-19) or limited to a small study cohort (20). 
Given the discrepancies in the evidence, we chose to explore this further in four frequently performed surgical procedures in one Australian tertiary referral hospital. These procedures were laparoscopic appendectomy (APP); laparoscopic cholecystectomy and intraoperative cholangiogram (CHOLE); THR; and hysteroscopy with dilation and curettage (DC). The specific objectives of the study were (i) to determine the prevalence of overweight and obesity in the cohort of surgical patients chosen and (ii) to evaluate the association between BMI and resource utilisation outcomes (procedural duration, anaesthetic duration, intensive care stay, total hospital stay and cost) in these surgical procedures.

\section{$\underline{\text { Methods }}$}

This retrospective cohort study included patients undergoing four surgical procedures at a regional tertiary referral hospital between 01 January 2016 and 31 December 2016. This hospital is the major acute care hospital in a regional Health District and performs approximately 13000 surgical procedures per year. (21). Ethical approval for the study was obtained from the joint Illawarra Shoalhaven Local Health District (ISLHD) / University of Wollongong Human Research Ethics Committee (HE2017/370).

Data was obtained from the Illawarra Health Information Platform (IHIP), a non-identifiable health databank and health records linkage system (22). Data included admitted patient data, electronic medical record extracts, operating theatre data and cost data. Procedural duration was time from placement on the operating table to final dressings were applied. Anaesthetic duration was time from arrival in the anaesthetic waiting bay to arrival in the post anaesthetic care unit. Australian Government definitions (23) for overweight and obesity were used to stratify patients, with underweight defined as BMI $<18 \mathrm{~kg} / \mathrm{m}^{2}$; a healthy weight BMI 18.5- 
$24.9 \mathrm{~kg} / \mathrm{m}^{2}$; overweight BMI of 25-29.9kg/m² ; and obesity BMI > $30 \mathrm{~kg} / \mathrm{m}^{2 \cdot}$ Information included in the supplementary tables defines Class I obesity as BMI 30-34.99 kg/m²; Class II as BMI 35-39.99 kg/m²; and Class III obesity as a BMI $>40 \mathrm{~kg} / \mathrm{m}^{2}$.

Eligible patients for the study were identified using the Australian Classification of Health Intervention Codes (ACHI) (24) of: laparoscopic appendectomy (ACHI code 30572-00 [926]); laparoscopic cholecystectomy and intraoperative cholangiogram (ACHI code 3044500 [965]); total hip replacement (ACHI codes 48318-00 and 49319-00 [1489]); and hysteroscopy with dilation and curettage (ACHI code 35640-00 [1265]). Inclusion criteria were all non-pregnant adults over 18 years of age that had undergone one of the four surgical procedures of interest under general anaesthesia. Exclusion criteria were patients in whom multiple procedures were performed or individuals with incomplete BMI data.

Cost data was obtained from the Activity Based Management portal (25). Costs included the total cost, medical, nursing, allied health, imaging, operating room, pathology, critical care, on costs, non-clinical, pharmacy, excluded, specialist procedure suite, prosthetics, and ward supply costs for each episode of care. The five highest cost categories were reported in addition to total cost.

All statistical analysis was undertaken using SPSS version 24.0 (IBM, Armonk, New York, USA). Normality was assessed using the Shapiro Wilk test. Non-normally distributed data are reported as median and interquartile range. A binomial test was used to compare prevalence of overweight and obesity in the study cohort with local (26) and national population prevalence estimates (3). Associations between categorical variables were evaluated using the 
Chi Square test. Differences between groups (e.g. BMI categories) were analysed using the Kruskal Wallis tests for continuous variables. Hierarchical linear regression was used to assess the association between BMI and the outcomes of LOS, operative and anaesthetic duration and all cost categories. Standardised beta coefficients and the 95\% confidence interval are reported for each model after controlling for potential confounders of age, gender and comorbidities (measured using the Charlson Comorbidity Index score (27). All statistical tests were two-sided, with a p value of 0.05 considered statistically significant.

\section{$\underline{\text { Results }}$}

A total of 1098 individuals were identified. The number of eligible individuals with missing BMI data was 399 (36.3\%). The proportion with missing data varied from 2.4\% (THR, $n=4)$; 7.8\% (D\&C, $n=12) ; 42.5 \%$ (CHOLE, $n=152) ; 55.1 \%$ (APP, $n=231$ ). The main reason for missing BMI data was omission of a height measurement. The mean weight in the individuals with missing BMI data was 76.1 kg (APP group); 108.7 kg (D\&C); 81.8 kg (CHOLE) and 91.3kg (THR). This was not substantially different from the mean weight of included individuals. There were also no significant differences between excluded and included participants for gender or LOS. However, those with missing BMI data in the APP group were significantly younger $(\mathrm{p}<0.0001)$.

The final study population consisted of 699 individuals. Males comprised approximately half of patients undergoing APP (48.4\%) and THR (49.7\%), The median (IQR) age of individuals ranged from 34 years (IQR: 24-48) for APP; to 70 years (IQR: 59-78) for THR. In the APP group, there were significant differences in age between the BMI categories (Table S1, $\mathrm{p}=0.001)$. 
The proportion of surgical patients who were overweight ranged from 85.9\% (THR group) to 57.4\% (APP group). The proportion who were obese varied from 27.7\% (APP group) to 53.4\% (CHOLE group) (Table 1). Very few patients were underweight.

BMI was not associated with worse outcomes in any of the four surgical procedures (Table 2). Underweight individuals were excluded from the costing analysis as they comprised less than five individuals in each cohort. Individuals who were overweight or obese did not cost significantly more than normal weight individuals in any surgical group (Table S2). After controlling for the effects of age, gender and comorbidities there was a significant positive association between BMI and LOS (Table S3, $\mathrm{p}<0.05$ ), medical costs and allied health costs for the APP group. For those who underwent CHOLE, there was also a significant positive association between BMI and critical care costs $(\mathrm{p}<0.0001)$.

In contrast, there was either no association or a negative association between BMI and outcomes in the other types of surgical procedures studied. For example, in the THR group, a high BMI was associated with shorter LOS, and lower total costs and medical costs. There was also a significant negative association between BMI and nursing costs in those undergoing DC, CHOLE and THR (Table S3).

\section{Discussion}

The high prevalence of overweight and obesity in the Australian community (3) was reflected in the present study. A high proportion of individuals were overweight or obese at the time of surgery. However, BMI was not associated with increased hospital resource utilisation in any of the four surgical procedures examined after controlling for age, gender and complexity. For other outcomes of hospital resource utilisation, such as total length of stay and cost, the 
relationship appears to be more complex, and outcomes were inconsistent across the four procedures examined in this study.

The prevalence of obesity in our surgical sample was also significantly higher than local (26) and national (3) population prevalence estimates for all procedures except appendectomy. This is consistent with evidence that obesity is associated in the pathophysiology of the development of cholelithiasis (28), arthropathies (29), and gynaecological bleeding (30), but not appendicitis (31). This is also consistent with previous research on obesity in surgical populations. For example, the prevalence of obesity in those requiring THR or total knee replacement was significantly greater than the general population (29). These findings were supported in another study that reported substantial increases in the prevalence of obesity [increasing from $14.9 \%$ to $20.6 \%$ ( $\mathrm{p}<0.001)$ ] and morbid obesity [increasing from $7.1 \%$ to $14.8 \%$ ( $\mathrm{p}<0.001)$ ] among surgical patients between 1989-1991, compared to those whose procedure occurred between 2006-2008 (32).

Several findings were in contrast to the broader literature. For example, a high BMI in the current study was associated with lower hospital costs in some procedures (e.g. patients undergoing THR, CHOLE or DC). These findings are not consistent with previous research which suggests that obesity is associated with increased costs in a range of surgical procedures, including those examined in this study (33). Of note, in one of the largest studies to date, Mason et al (34) conducted an analysis of more than 2 million non-bariatric surgical procedures and reported that obesity was associated with a significant increased LOS (34). The findings in the present study regarding the cost of appendectomy is much lower than the cost found in a recent Australian study (35). This may represent greater efficiencies due to a dedicated acute surgical unit. 
Reasons for the inconsistency of association between BMI and outcomes in the four surgical procedures examined in this study are not clear. This may be due to variations in the data collection systems used. Inconsistencies in the definitions used by coders for anaesthetic and surgical duration are also possible. Similarly, procedure times may not include delays before and during an operation that can be variable and operator dependent.

Documenting the overrepresentation of obesity in the surgical population is highly important from a pragmatic perspective. Obese patients require more extensive care, including bariatric equipment and additional staff time to assist with peri-operative care (36). Future research to explore the relationship between BMI and outcomes in other surgical procedures is needed. In addition, recording patient complexity, and stricter measures of anaesthetic and procedural duration would be beneficial. Longitudinal analyses with larger sample sizes exploring one procedure may also be informative. Recording patient resource consumption may help explain relative differences in patient expenses and may facilitate benchmarking.

Given the high prevalence of obesity in the surgical populations, public discussion regarding appropriate weight management options warrants consideration. This includes strategies such as perioperative rehabilitation, bedside motivational interviewing, team care arrangements and linkage with dietetics to facilitate behavioural change. Unless the issues associated with obese patients are addressed, obese patients will continue to experience worse health outcomes including post-operative complications (37).

This study also suggests that being underweight rather obese may be more problematic for some surgical procedures. For instance, those who were underweight and had a THR in the 
present study had an increased mortality rate (data not shown), and higher total costs associated with their care ( $\mathrm{p}=0.02$, data not shown). However our patient numbers were very small ( $\mathrm{n}=<5$ in each surgical group). Further investigation with larger cohorts of underweight patients may be of value. Previous studies indicate that underweight patients have poorer outcomes compared to those with a healthy BMI (12). Some of the reasons for worse outcomes in underweight patients include; deconditioning, malnutrition, low preoperative haemoglobin and poor baseline status $(38,39)$. The poorer outcomes and higher costs may also be related to the high prevalence of malnutrition in older patient populations who present for THR, especially among those who present after a fall or with a fractured neck of femur (40). Guidelines to counsel underweight or malnourished patients to improve nutritional status prior to surgery may be of benefit in this vulnerable population.

This study has several strengths including completeness of the data regarding BMI for the THR and D\&C procedures surgical and anaesthetic duration times, costs, and use of the Charlson index score to describe complexity of the patients. However, there are limitations. This includes excluding 55.1\% and $42.5 \%$ of the appendectomy and cholecystectomy study population due to missing BMI data. This may have potentially introduced a selection bias. The relatively small sample in each of the four surgical cohorts analysed in this study may also limit generalisability. We were unable to extract the American Society of Anaesthesiologists physical classification scores to stratify patients according to disease burden (41) and the technical difficulty of the surgery for a significant portion of patients, making it difficult to account for relative patient complexity as commonly reported in previous studies $(34,42)$. The impact of unmeasured variables, such as procedural and anaesthetic delays, and variation in operator experience and perioperative delays on operating times were not recorded, and all of these are possible confounding variables. The proportion 
of elective surgeries varied between surgical types and this may have also had a bearing on outcome parameters. Postoperative complications and readmissions were also not recorded in the data set examined. The study is cross sectional in nature and further research from a longitudinal perspective is warranted. Another important limitation is that it was difficult to compare costs of surgery locally with international studies due to variations in the funding models used to calculate cost and charges for the different procedures.

\section{CONCLUSION}

This study highlights the high prevalence of overweight and obesity among patients undergoing four common surgical procedures. Our findings suggest that overweight and obesity are not consistently associated with worse outcomes and higher costs among patients undergoing these procedures. The only procedure in the current study associated with a longer length of stay and higher medical and allied health costs after adjusting for age, gender and patient complexity was appendectomy. Since the opposite appeared to be apparent for the other procedures, further research into these areas is warranted.

\section{Acknowledgments:}

Thanks to Brendan McAlister, Integration Development Coordinator at CHRISP for data extraction 


\section{References}

1. Collaborators TGO. Health Effects of Overweight and Obesity in 195 Countries over 25 Years. New England Journal of Medicine. 2017;377(1):13-27.

2. Tremmel M, Gerdtham U-G, Nilsson PM, Saha S. Economic Burden of Obesity: A Systematic Literature Review. International Journal of Environmental Research and Public Health. 2017;14(4):435.

3. Australian Bureau of Statistics. Australian Health Survey: Biomedical Results for Chronic Diseases, 2011-12. . ABS, Canberra, 2013.

4. Sun J, Zhou W, Gu T, Zhu D, Bi Y. A retrospective study on association between obesity and cardiovascular risk diseases with aging in Chinese adults. Scientific Reports. 2018;8(1):5806.

5. Tjeertes EEKM, Hoeks SSE, Beks SS, Valentijn TTM, Hoofwijk AAGM, Stolker RJRJ. Obesity - a risk factor for postoperative complications in general surgery? BMC Anesthesiology. 2015;15:112.

6. Durup-Dickenson M, Nicolajsen CW, Budtz-Lilly J, Laustsen J, Eldrup N. Body Mass Index and Operating Times in Vascular Procedures. EJVES Short Reports. 2017;35:19-23.

7. Nørtoft E, Chubb B, Borglykke A. Obesity and healthcare resource utilization: comparative results from the UK and the USA. Obesity Science \& Practice. 2018;4(1):41-5.

8. Bell SW, Warrier SK. Optimization of bodyweight before visceral surgery in obese patients. British Journal of Surgery. 2017;104(6):646-7.

9. Bohmer AB, Wappler F. Preoperative evaluation and preparation of the morbidly obese patient. Current opinion in anaesthesiology. 2017;30(1):126-32.

10. Xie P, Li Z, Tian Z. The optimal combination of mechanical ventilator parameters under general anesthesia in obese patients undergoing laparoscopic surgery. Journal of clinical anesthesia. 2016;34:290-4.

11. Members of the Working P, Nightingale CE, Margarson MP, Shearer E, Redman JW, Lucas DN, et al. Peri-operative management of the obese surgical patient 2015. Anaesthesia. 2015;70(7):859-76.

12. Valentijn TM, Galal W, Tjeertes EKM, Hoeks SE, Verhagen HJ, Stolker RJ. The obesity paradox in the surgical population. The Surgeon. 2013;11(3):169-76.

13. Kremers HM, Visscher SL, Kremers WK, Naessens JM, Lewallen DG. Obesity increases length of stay and direct medical costs in total hip arthroplasty. Clinical Orthopaedics and Related Research $^{\circledR}$. 2014;472(4):1232-9.

14. Haverkamp D, Klinkenbijl MN, Somford MP, Albers GH, van der Vis HM. Obesity in total hip arthroplasty--does it really matter? A meta-analysis. Acta orthopaedica. 2011;82(4):417-22.

15. McCalden RW, Charron KD, MacDonald SJ, Bourne RB, Naudie DD. Does morbid obesity affect the outcome of total hip replacement?: an analysis of 3290 THRs. The Journal of bone and joint surgery British volume. 2011;93(3):321-5.

16. Australian Institute of Health and Welfare. ACHI (8th edition) procedure data cubes 2017 [March 13, 2018]. Available from: https://www.aihw.gov.au/reports/hospitals/procedures-datacubes/contents/data-cubes.

17. Mason RJ, Moazzez A, Moroney JR, Katkhouda N. Laparoscopic vs open appendectomy in obese patients: outcomes using the American College of Surgeons National Surgical Quality Improvement Program database. Journal of the American College of Surgeons. 2012;215(1):88-99; discussion -100 .

18. Ciarrocchi A, Amicucci G. Laparoscopic versus open appendectomy in obese patients: A meta-analysis of prospective and retrospective studies. J Minim Access Surg. 2014;10(1):4-9. 19. Workgroup of the American Association of Hip and Knee Surgeons Evidence Based Committee. Obesity and total joint arthroplasty: a literature based review. The Journal of arthroplasty. 2013;28(5):714-21. 
20. Chen CCG, Collins SA, Rodgers AK, Paraiso MFR, Walters MD, Barber MD. Perioperative complications in obese women vs normal-weight women who undergo vaginal surgery. American Journal of Obstetrics \& Gynecology. 2007;197(1):98.e1-.e8.

21. NSW Ministry of Health. NSW Hospital Peer Groups 2016. [Document Number IB2016_013] 2016 [Available from: http://www1.health.nsw.gov.au/pds/ActivePDSDocuments/IB2016 013.pdf.

22. Centre for Health Research Illawarra Sholhaven Population. IHIP data 2018 [Available from: https://ahsri.uow.edu.au/chrisp/ihip-data/index.html

23. Australian Institute of Health and Welfare. Australia's health 2018. . Canberra2018

24. Independent Hospital Pricing Authority. ACHI The Australian Classification of Health Interventions Alphabetic Index Australian Consortium for Classification Development 2015.

25. Taskforce ABF. NSW ABM and Funding Compendium 2015/2016. . 71 Miller Street North Sydney, NSW.2015.

26. Ghosh A, Charlton KE, Girdo L, Batterham M. Using data from patient interactions in primary care for population level chronic disease surveillance: The Sentinel Practices Data Sourcing (SPDS) project. BMC public health. 2014;14:557.

27. Charlson ME, Pompei P, Ales KL, Mackenzie CR. A new method of classifying prognostic comorbidity in longitudinal studies: development and validation. Journal of chronic diseases. 1987;40(5):373-83.

28. Kharga B, Sharma BK, Singh VK, Nishant K, Bhutia P, Tamang R, et al. Obesity Not Necessary, Risk of Symptomatic Cholelithiasis Increases as a Function of BMI. Journal of Clinical and Diagnostic Research : JCDR. 2016;10(10):PC28-PC32.

29. Harms S, Larson R, Sahmoun AE, Beal JR. Obesity increases the likelihood of total joint replacement surgery among younger adults. International Orthopaedics. 2007;31(1):23-6.

30. Nouri M, Tavakkolian A, Mousavi SR. Association of dysfunctional uterine bleeding with high body mass index and obesity as a main predisposing factor. Diabetes \& Metabolic Syndrome: Clinical Research \& Reviews. 2014;8(1):1-2.

31. Towfigh S, Chen F, Katkhouda N, Kelso R, Sohn H, Berne TV, et al. Obesity should not influence the management of appendicitis. Surgical Endoscopy. 2008;22(12):2601-5.

32. Hamlin RJ, Sprung J, Hofer RE, Schroeder DR, Weingarten TN. Obesity Trends in the Surgical Population at a Large Academic Center: A Comparison between 1989-1991 to 2006-2008 Epochs. Acta Chirurgica Belgica. 2013;113(6):397-400.

33. Lowndes B, Thiels CA, Habermann EB, Bingener J, Hallbeck S, Yu D. Impact of patient factors on operative duration during laparoscopic cholecystectomy: evaluation from the National Surgical Quality Improvement Program database. American journal of surgery. 2016;212(2):289-96.

34. Mason RJ, Moroney JR, Berne TV. The cost of obesity for nonbariatric inpatient operative procedures in the United States: national cost estimates obese versus nonobese patients. Ann Surg. 2013;258(4):541-51; discussion 51-3.

35. Wang E, Jootun R. Management of acute appendicitis in an acute surgical unit: a cost analysis. 2018.

36. Lukosiute A, Karmali A, Cousins JM. Anaesthetic Preparation of Obese Patients: Current Status on Optimal Work-up. Current obesity reports. 2017;6(3):229-37.

37. Zusmanovich M, Kester BS, Schwarzkopf R. Postoperative complications of total joint arthroplasty in obese patients stratified by BMI. The Journal of arthroplasty. 2018;33(3):856-64. 38. Ellsworth B, Kamath AF. Malnutrition and Total Joint Arthroplasty. Journal of nature and science. 2016;2(3):e179.

39. Kamath AF, McAuliffe CL, Kosseim LM, Pio F, Hume E. Malnutrition in Joint Arthroplasty: Prospective Study Indicates Risk of Unplanned ICU Admission. Archives of Bone and Joint Surgery. 2016;4(2):128-31. 
40. Ihle C, Freude T, Bahrs C, Zehendner E, Braunsberger J, Biesalski HK, et al. Malnutrition - An underestimated factor in the inpatient treatment of traumatology and orthopedic patients: A prospective evaluation of 1055 patients. Injury. 2017;48(3):628-36.

41. Hurwitz EE, Simon M, Vinta SR, Zehm CF, Shabot SM, Minhajuddin A, et al. Adding Examples to the ASA-Physical Status Classification Improves Correct Assignment to Patients. Anesthesiology. 2017;126(4):614-22.

42. Hawn MT, Bian J, Leeth RR, Ritchie G, Allen N, Bland KI, et al. Impact of Obesity on Resource Utilization for General Surgical Procedures. Annals of Surgery. 2005;241(5):821-8. 
Table S1. Descriptive characteristics according to procedure and BMI category.

\begin{tabular}{|c|c|c|c|c|c|c|c|c|}
\hline & $\begin{array}{c}\text { Underweight } \\
\text { BMI }<18.5 \mathrm{~kg} / \mathrm{m}^{2}\end{array}$ & $\begin{array}{c}\text { Healthy weight } \\
\text { BMI 18.5-24.99 } \\
\mathrm{kg} / \mathrm{m}^{2}\end{array}$ & $\begin{array}{c}\text { Overweight } \\
\text { BMI } 25-29.99 \mathrm{~kg} / \mathrm{m}^{2}\end{array}$ & $\begin{array}{c}\text { Obese class I } \\
\text { BMI 30-34.99 } \\
\text { kg/m }\end{array}$ & $\begin{array}{c}\text { Obese class II } \\
\text { BMI 35-39.99 } \\
\mathrm{kg} / \mathrm{m}^{2}\end{array}$ & $\begin{array}{l}\text { Obese class III } \\
\text { BMI }>40 \mathrm{~kg} / \mathrm{m}^{2}\end{array}$ & Total & $P$ value \\
\hline \multicolumn{9}{|l|}{\begin{tabular}{|l|} 
Appendectomy \\
\end{tabular}} \\
\hline \begin{tabular}{|l|} 
Number (\%) \\
\end{tabular} & $\#$ & $78(41.5)$ & $54(28.7)$ & $27(14.4)$ & $15(8.0)$ & $10(5.3)$ & 188 & -- \\
\hline Males n (\%) & $\#$ & 36 (39.6) & $25(27.5)$ & $16(17.6)$ & $6(6.6)$ & $6(6.6)$ & $91(48.4)$ & 0.78 \\
\hline Age (years) & $\begin{array}{c}31.5 \\
(21-62.3)\end{array}$ & $\begin{array}{c}27 \\
(21-39)\end{array}$ & $\begin{array}{c}35 \\
(27-50.3)\end{array}$ & $\begin{array}{c}37 \\
(30.8-48.8)\end{array}$ & $\begin{array}{c}40 \\
(22.5-58.3)\end{array}$ & $\begin{array}{c}49.5 \\
(39.8-70.8)\end{array}$ & $\begin{array}{c}34 \\
(24-48)\end{array}$ & 0.001 \\
\hline Weight (kg) & $\begin{array}{c}53 \\
(51-54.8)\end{array}$ & $\begin{array}{c}64 \\
(57-73)\end{array}$ & $\begin{array}{c}80 \\
(72-85.3)\end{array}$ & $\begin{array}{c}91 \\
(88-99.6)\end{array}$ & $\begin{array}{c}102 \\
(91.6-121.2)\end{array}$ & $\begin{array}{c}115 \\
(110.7-127.4)\end{array}$ & $\begin{array}{c}76 \\
(64.7-90)\end{array}$ & - \\
\hline \multicolumn{9}{|c|}{ Hysteroscopy with dilatation and curettage } \\
\hline Number (\%) & $\#$ & $36(25.4)$ & $25(17.6)$ & $24(16.9)$ & $23(16.2)$ & $31(21.8)$ & 142 & - \\
\hline Males (n/\%) & \# & 0 & 0 & 0 & 0 & 0 & 0 & - \\
\hline Age (years) & $\begin{array}{c}43 \\
(19.7-43.8)\end{array}$ & $\begin{array}{c}44.5 \\
(35.4-58.2)\end{array}$ & $\begin{array}{c}47 \\
(32-55)\end{array}$ & $\begin{array}{c}54.5 \\
(44.4-67.2)\end{array}$ & $\begin{array}{c}55 \\
(41.7-61.8)\end{array}$ & $\begin{array}{c}47 \\
(39.5-54)\end{array}$ & $\begin{array}{c}47.5 \\
(37.9-60)\end{array}$ & 0.08 \\
\hline Weight (kg) & $\begin{array}{c}39 \\
(36.5-56)\end{array}$ & $\begin{array}{c}59 \\
(55.2-63.8)\end{array}$ & $\begin{array}{c}71.2 \\
(69-75.6)\end{array}$ & $\begin{array}{c}85.5 \\
(78.5-92.6)\end{array}$ & $\begin{array}{c}98 \\
(84.1-107.2)\end{array}$ & $\begin{array}{c}120 \\
(115-129)\end{array}$ & $\begin{array}{c}80 \\
(66.4-108)\end{array}$ & - \\
\hline \multicolumn{9}{|c|}{ Laparoscopic Cholecystectomy } \\
\hline Number (\%) & 0 & $30(14.6)$ & $66(32)$ & $46(22.3)$ & $26(12.6)$ & $38(18.4)$ & 206 & - \\
\hline Males (n/\%) & 0 & $10(16.8)$ & $26(33.8)$ & $15(19.5)$ & $5(6.5)$ & $21(27.3)$ & $77(37.3)$ & 0.05 \\
\hline Age (years) & 0 & $\begin{array}{c}50.5 \\
(32-76.1)\end{array}$ & $\begin{array}{c}58 \\
(39.9-73)\end{array}$ & $\begin{array}{c}57 \\
(39.8-78)\end{array}$ & $\begin{array}{c}46 \\
(36-69.1)\end{array}$ & $\begin{array}{c}56 \\
(43.6-73)\end{array}$ & $\begin{array}{c}55 \\
(38-73.1)\end{array}$ & 0.57 \\
\hline
\end{tabular}




\begin{tabular}{|c|c|c|c|c|c|c|c|c|}
\hline Weight (kg) & 0 & $\begin{array}{c}65 \\
(58-73.4)\end{array}$ & $\begin{array}{c}77 \\
(70-85.1)\end{array}$ & $\begin{array}{c}86 \\
(80-101.2)\end{array}$ & $\begin{array}{c}102 \\
(91.3-123)\end{array}$ & $\begin{array}{c}120 \\
(115.8-127.5)\end{array}$ & $\begin{array}{c}84 \\
(73.6-105)\end{array}$ & - \\
\hline \multicolumn{9}{|c|}{ Total Hip Replacement } \\
\hline Number (\%) & $\#$ & $21(12.9)$ & $62(38)$ & $42(25.8)$ & $24(14.7)$ & $12(7.4)$ & 163 & - \\
\hline Males (n/\%) & $\#$ & 10 & $34(42)$ & $18(22.2)$ & $15(18.5)$ & $4(4.9)$ & $81(49.7)$ & 0.28 \\
\hline Age (years) & $\begin{array}{c}82 \\
(76-88)\end{array}$ & $\begin{array}{c}62 \\
(53-75.7)\end{array}$ & $\begin{array}{c}70 \\
(58.9-76)\end{array}$ & $\begin{array}{c}67.5 \\
(60.8-80.1)\end{array}$ & $\begin{array}{c}71 \\
(57.7-78)\end{array}$ & $\begin{array}{c}74 \\
(71-80)\end{array}$ & $\begin{array}{c}70 \\
(59-78)\end{array}$ & 0.13 \\
\hline Weight (kg) & $\begin{array}{c}53.6 \\
(49-58.1)\end{array}$ & $\begin{array}{c}64.5 \\
(57-75)\end{array}$ & $\begin{array}{c}78.2 \\
(72.4-84.2)\end{array}$ & $\begin{array}{c}93 \\
(82.3-99.9)\end{array}$ & $\begin{array}{c}101 \\
(95.7-110.1)\end{array}$ & $\begin{array}{c}115.5 \\
(107.8-137.2)\end{array}$ & $\begin{array}{c}85 \\
(74.8-97.8)\end{array}$ & - \\
\hline
\end{tabular}

\# Data suppressed due to cell size $<5$ 
Table S2. Unadjusted median costs (2016 \$AUD) between normal weight, overweight and obese patients for four surgical procedures

\begin{tabular}{|c|c|c|c|c|}
\hline Item costs, \$AUD median (IQR) & $\begin{array}{c}\text { Normal weight } \\
\left(\mathrm{BMI} 18.5-24.9 \mathrm{~kg} / \mathrm{m}^{2}\right)\end{array}$ & $\begin{array}{c}\text { Overweight } \\
\left.\text { (BMI 25-29.99 kg / } \mathrm{m}^{2}\right)\end{array}$ & $\begin{array}{c}\text { Obese } \\
\left(\text { BMI }>30 \mathrm{~kg} / \mathrm{m}^{2}\right)\end{array}$ & P value \\
\hline \multicolumn{5}{|l|}{ Appendectomy } \\
\hline Medical & $621(466-920)$ & 432 (342-661) & $910(605-1430)$ & 0.02 \\
\hline Nursing & 578 (356-849) & $554(352-878)$ & $604(401-1000)$ & 0.61 \\
\hline Allied & $3.2(1.4-9.7)$ & $2.1(1.0-5.3)$ & $7.8(2.0-13.4)$ & 0.009 \\
\hline Operating Room & $2510(1878-3337)$ & $2491(1881-3433)$ & $2821(2242-3918)$ & 0.41 \\
\hline Total Cost & $5504(4191-7585)$ & $5585(4112-8383)$ & $6527(5236-9162)$ & 0.01 \\
\hline \multicolumn{5}{|c|}{ Hysteroscopy with dilatation and curettage } \\
\hline Medical & $70(50-216)$ & $59(45-105)$ & $70(53-126)$ & 0.82 \\
\hline Nursing & $114(73-319)$ & $80(54-140)$ & $96(73-152)$ & 0.49 \\
\hline Allied & $0.4(0.1-0.7)$ & $0.2(0.1-0.5)$ & $0.3(0.1-0.5)$ & 0.55 \\
\hline Operating Room & $1456(1205-2132)$ & $1288(940-1553)$ & 1367 (1088-1749) & 0.56 \\
\hline Total Cost & 2093 (1910-4048) & 1765 (1522-2577) & 1966 (1633-2527) & 0.49 \\
\hline \multicolumn{5}{|l|}{ Laparoscopic Cholecystectomy } \\
\hline Medical & $1259(498-2180)$ & $1090(567-2153)$ & $880(505-1773)$ & 0.14 \\
\hline Nursing & $1559(875-2937)$ & $1488(765-2470)$ & $1188(673-1987)$ & 0.08 \\
\hline Allied & $9.6(4.3-43.3)$ & $10.2(2.6-139.6)$ & $12.8(5.4-47.8)$ & 0.31 \\
\hline Critical Care & $0(0-0)$ & $0(0-0)$ & $0(0-0)$ & 0.88 \\
\hline Operating Room & $3570(2732-5277)$ & 3777 (2960-4838) & 3757 (2861-5025) & 0.91 \\
\hline Total Cost & $10979(6070-16126)$ & $8670(6105-13135)$ & $8281(6288-11929)$ & 0.84 \\
\hline \multicolumn{5}{|l|}{ Total Hip Replacement } \\
\hline Medical & $1143(852-1771)$ & $1100(860-1563)$ & $1058(828-1549)$ & 0.62 \\
\hline Nursing & $1518(1216-2362)$ & $1543(1175-2312)$ & $1460(1137-2183)$ & 0.92 \\
\hline Allied & 817 (632-1048) & $832(667-975)$ & 762 (616-948) & 0.31 \\
\hline Operating Room & 4538 (3464-6387) & $4411(3413-5222)$ & $4463(2992-5182)$ & 0.95 \\
\hline Total Cost & 19738 (16627-21299) & 18253 (16476-20928) & 17936 (1495-20505) & 0.08 \\
\hline
\end{tabular}

Costs for critical care not included for appendectomy, hysteroscopy with dilatation and curettage, and total hip replacement as there were no critical care stays. 
Table S3. Standardized regression coefficients for hierarchical regression analyses evaluating the association between BMI and various outcomes.

All analyses are adjusted for age, gender, and patient complexity measured using the Charlson Comorbidity Index score.

\begin{tabular}{|l|c|c|c|c|}
\hline & Appendectomy & D\&C & $\begin{array}{c}\text { Laparoscopic } \\
\text { cholecystectomy }\end{array}$ & THR \\
\hline $\begin{array}{l}\text { standardized } \\
\text { B coefficient }\end{array}$ & $\begin{array}{c}\text { standardized B } \\
\text { coefficient }\end{array}$ & $\begin{array}{c}\text { standardized } \\
\text { B coefficient }\end{array}$ & $\begin{array}{c}\text { standardized } \\
\text { B coefficient }\end{array}$ \\
\hline $\begin{array}{l}\text { Anaesthetic } \\
\text { duration }\end{array}$ & $0.053^{* *}$ & $-0.072^{*}$ & -0.163 & $-0.15^{*}$ \\
\hline $\begin{array}{l}\text { Procedure } \\
\text { duration }\end{array}$ & 0.028 & 0.051 & 0.066 & -0.096 \\
\hline $\begin{array}{l}\text { Hours in } \\
\text { ICU }\end{array}$ & N/A & -0.09 & 0.008 & -0.113 \\
\hline Costs & 0.11 & N/A & 0.016 & N/A \\
\hline $\begin{array}{l}\text { Total } \\
\text { Medical }\end{array}$ & $0.18^{* *}$ & -0.135 & $-0.196^{*}$ & $-0.103^{* *}$ \\
\hline Nursing & 0.096 & $-0.128^{* *}$ & $-0.167^{*}$ & $-0.105^{*}$ \\
\hline $\begin{array}{l}\text { Allied } \\
\text { health }\end{array}$ & $0.096^{* *}$ & $-0.095^{* *}$ & -0.122 & -0.147 \\
\hline Critical care & 0.046 & N/A & $0.026^{*}$ & N/A \\
\hline $\begin{array}{l}\text { Operating } \\
\text { room }\end{array}$ & 0.06 & -0.069 & -0.019 & -0.046 \\
\hline
\end{tabular}

${ }^{*}=\mathrm{p}<0.0001 ;{ }^{* *} \mathrm{p}<0.05 ; \mathrm{N} / \mathrm{A}$ : not applicable as no hours in critical care / ICU 